\title{
Barriers to Care for Antenatal Depression
}

\author{
Robin Cook Kopelman, M.D., M.P.H., Joy Moel, Ph.D., Carol Mertens, Ph.D., Scott Stuart, \\ M.D., Stephan Arndt, Ph.D., and Michael W. O'Hara, Ph.D. \\ University of lowa, lowa City. Dr. Kopelman, Dr. Moel, Dr. Stuart, and Dr. Arndt are affiliated with \\ the Department of Psychiatry. Dr. Stuart is also affiliated with the Department of Psychology, with \\ which Dr. O'Hara is affiliated. Dr. Mertens is with the Department of Radiology
}

\section{Abstract}

Objective-This study examined the individual-level factors impacting pregnant women's access to mental health treatment for depression.

Methods-A total of 1,416 pregnant women receiving prenatal care completed measures of depressive symptomatology, willingness to seek treatment for depression or anxiety, and perceived barriers to seeking such care.

Results-Women with Beck Depression Inventory scores \{greater than or equal to; 2$\} 16$ (indicating possible depression) $(\mathrm{N}=183)$ were more likely than women with lower scores $(\mathrm{N}=1,233)$ to identify the following barriers: cost, lack of insurance, lack of transportation, long waits for treatment, previous bad experience with mental health care, and not knowing where to go for treatment. Lower income was correlated with increased endorsement of cost and transportation as barriers.

Conclusions-Results suggest that addressing financial and logistical barriers through changes in mental health services and policy will improve access to care for antenatal depression. However, attending to these issues alone will not address additional important barriers to care such as lack of trust.

Antenatal depression affects approximately $10 \%$ of women during pregnancy (1), and rates among low-income pregnant women may be as high as $27.6 \%$ (2). It is associated with psychological and physical morbidity, including poor birth outcomes (3), and increased rates of suicide (4).

Study of perinatal mental health services is critical both because of these negative sequelae and because the perinatal period presents a unique window of opportunity for more frequent contact with the health system. Preventive and care coordination resources are often available during pregnancy, although they may not be available at other times. This is especially true for low-income women, the majority of whom receive their health care exclusively in the obstetric setting (5).

Despite the increased contact of pregnant women with the health system, low rates of antenatal depression detection have been well documented (6). Moreover, although there is evidence that treatment is effective $(7,8)$, many pregnant women with depression go untreated (9), and poor women are particularly unlikely to access mental health treatment

Send correspondence to Dr. Kopelman at the Department of Psychiatry, University of Iowa, 2-202 MEB, Iowa City, IA 52242 (robincook@uiowa.edu).

disclosures The authors report no competing interests. 
(10). Although some studies have documented which pregnant women are more likely to be receiving mental health care (9), they have not examined why many do not.

The few studies examining barriers to depression care for women have identified financial and logistical barriers $(6,11)$. Although cost is especially relevant for low-income women (2), many of these women have access to Medicaid during pregnancy, suggesting the existence of other potentially unique barriers.

This study explored patient-level barriers to mental health care, with an emphasis on lowincome pregnant women. The goals were to establish how willing pregnant women were to seek treatment for depression or anxiety, as well as to examine the primary factors that might have an impact on their access to care. We hypothesized that a lower income level and a higher degree of depressive symptomatology would each be associated with greater perceived barriers to treatment.

\section{Methods}

We used a mixed-methods approach with qualitative and quantitative data obtained simultaneously (concurrent nested strategy) (12). Participants were recruited from four maternal health centers and a university-based obstetric clinic. The maternal health centers are funded by the state's Department of Human Services to serve women who have limited means to pay for perinatal care. Focus groups were conducted with women from the maternal health centers to gain additional perspective on barriers to and facilitators of helpseeking for depression among low-income pregnant women. Women were eligible to participate if they were 18 years of age or older, were between six and 26 weeks of pregnancy, and spoke English. Study data were collected between December 2002 and December 2004. This study received approval from the University of Iowa Institutional Review Board. Written informed consent was obtained after a complete description of the study to participants.

Women receiving routine prenatal care were asked to participate in a research study examining the emotional experiences of women during pregnancy. The 1,416 eligible women who agreed to participate completed three questionnaires during their clinic appointment. Data were not available for how many women were approached to participate in the study.

Sociodemographic data were collected. The Beck Depression Inventory (BDI) (13) was used to measure depressive symptoms. Possible scores on the BDI range from 0 to 63, with higher scores indicating more depressive symptomatology. The recommended cutoff score for screening antenatal women for depression is \{greater than or equal to; ㄱ\} 16 (14).

Women responded to the access to treatment questionnaire that we created for this study. The questionnaire used a 4-point scale regarding the women's hypothetical willingness to seek help from a health care professional for depression or anxiety during pregnancy (1, very willing, to 4 , not at all willing). Using a list of barriers developed with input from maternal health center staff, we asked women, on a 4-point scale, how much the identified barrier would affect their ability to seek treatment (1, not at all affect, to 4 , greatly affect).

Women were divided into two groups on the basis of their BDI cutoff score (that is, BDI score \{greater than or equal to; $\geq 16$ or BDI score $<16)$. T tests were conducted to examine differences between these groups. Degrees of freedom were adjusted for unequal variances of the group when necessary. Because income was assessed in discrete categories, Spearman's $r$ was used for correlations and is reported throughout. All parametric tests were done with nonparametric analogs. The results were similar. 
We conducted six focus groups with 28 pregnant women. Participants were recruited by using an informational brochure describing the study and via staff referral. An experienced facilitator conducted all groups by using a semistructured interview guide.

All focus groups were audiotaped. Note takers were present to record all verbal and nonverbal content. Three coders identified codes and themes by hand by listening to the recordings in their entirety and by using focus group notes. Segments related to the dominant themes were transcribed verbatim. Themes were extracted in an iterative fashion, with analysis of each focus group conducted before the next. We used a collaborative approach to analysis (15). This approach requires the coders to present their perceptions of the data to other team members and reach consensus about the meaning of data and its categorization. An auditor (a study team member not involved in the original coding) served as a check for the consensus judgments using focus group recordings, coding tables, transcribed segments, and notes to ensure that important data were not overlooked by the primary team.

\section{Results}

Table 1 presents the sociodemographic data for women participating in the survey and focus groups.

The focus groups generated the following themes: the role of symptom severity, financial barriers, logistical barriers, lack of available treatment, lack of knowledge about depression in pregnancy and where to get care for it, negative prior experiences with and lack of trust in care providers, the importance of support from partner, family, friends and providers, and the role of stigma. Specific questions about these issues were also asked in the survey.

Table 2 presents the responses of women as to how barriers would affect their ability to seek treatment, as well as the results of $t$ tests examining differential barrier endorsement between women with BDI scores \{greater than or equal to; $\geq\} 16$ and women with lower scores.

There were no between-group differences for women with BDI scores \{greater than or equal to; z) $16(\mathrm{~N}=183)$ and those with lower scores $(\mathrm{N}=1,233)$ regarding willingness to seek care. That is, $45 \%(\mathrm{~N}=81)$ of women with BDI scores \{greater than or equal to; 2$\} 16$ and $44 \%$ $(\mathrm{N}=543)$ of women with lower BDI scores indicated that they would be very willing to seek care for depression. Women in the focus groups said that they would be more likely to seek care when symptoms were mild (to prevent symptoms from getting worse) as well as when symptoms were severe (as a "last resort").

Two barriers were associated with income among women with BDI scores \{greater than or equal to; 2$\} 16$. As income increased, concern decreased about cost (Spearman's $r=-.24, p<$. 001) and about transportation (Spearman's $r=-.32, \mathrm{p}<.001$ ).

In the focus groups, insurance and cost barriers were described as affecting ability to seek care and the quality of care received. One woman stated, "If you have insurance or can afford it—oh, you're their favorite patient ... if you're very limited, they give you the least amount [of help] they can give you."

Logistical barriers, including lack of transportation, difficulties getting time off from work, and a lack of child care, were acknowledged by all participants. Women in focus groups noted that transportation problems were often caused by caused by problems with finances, but they added that distance to care also had an impact on transportation as a barrier. 
The limited availability of local mental health care was discussed in focus groups. Women reported problems finding a provider-especially one who accepted Medicaid or who offered office hours compatible with their schedules. Scheduling was more problematic if they had to travel long distances or lacked transportation or child care. Women in the focus groups identified as important barriers a lack of knowledge about where to go for treatment, as well their providers' and their own lack of knowledge about depression during pregnancy itself.

Women in focus groups with prior "bad" experiences indicated that providers did not take time to listen or dismissed their concerns as "hormonal." They expressed concern that the treatments offered were not always appropriate and viewed doctors as "pushing meds." This perception affected their trust in providers regarding fetal medication exposure.

Several women described experiences similar to a woman who said, "They [medical providers] say it [medication] is safe-take this three times or four times [a day], whenever you need it—but then you read that it's really dangerous ... so I lose my trust."

Focus group participants worried about other potential negative consequences of seeking mental health care, specifically mentioning fears of having one's children taken away.

Lack of partner support was endorsed by 33\% (N=60) of women with BDI scores \{greater than or equal to; $\geq 116$ as being at least "somewhat" of a barrier. Women in focus groups indicated that support from partners, family, friends, or a care provider was an important factor in their decision to get help. Many women thought support from someone who had sought treatment or who had been depressed during pregnancy would make it easier for them to seek services.

Stigma, reflected by endorsement of "what other people would think," was rated as the least significant barrier by women with BDI scores \{greater than or equal to; 건. Stigma was noted by many focus group participants and was sometimes specific to their role as childbearing women. As one woman said, "You get that look like, 'You shouldn't be having children if you need this kind of help.'”

\section{Discussion and conclusions}

The goal of this study was to explore pregnant women's barriers to mental health care with an emphasis on the impact of income and depressive symptomatology. Although the women with elevated BDI scores were generally willing to seek mental health care, they identified multiple barriers.

Our data suggest that, in addition to financial and logistical barriers, women were reluctant to trust providers to address concerns about antenatal depression and fetal medication exposure and were apprehensive about endangering their parental rights. The high rankings of barriers such as cost, insurance, and transportation, as well as their relevance to lowincome women, point to the need for service interventions, such as vouchers for transportation or telemedicine. However, even in studies providing funding for child care and transportation, extensive psychoeducation and outreach have been necessary to engage women in treatment (16).

Perhaps endorsement of cost as a barrier reflects the value women place on mental health care. Although for some women mental health care is less of a priority than paying for other family needs, other women may not view the benefits and detriments of mental health care as worth the cost. This may be particularly true for low-income pregnant women who perceive that the care being provided or to which they have access is inferior. 
Although some women attributed prior negative experiences to their limited income or insurance coverage, depressive symptoms themselves were related to an endorsement of this barrier. This may partially be a result of negative perceptions related to mood state, but it also could be the result of negative interactions with providers when discussing mental health (17). A BDI score \{greater than or equal to; 2$\} 16$ is not equivalent to a diagnosis of major depression, and many women with such a score will not require treatment. However, as maternal health providers increasingly use screening tools to determine who might require additional evaluation, the barriers that this group faces to further evaluation are increasingly relevant.

Many barriers identified in this study are similar to those identified by groups largely composed of low-income African-American or Hispanic women (6,11). Barrier endorsement can be attributed to racial and ethnic differences (11). Our sample was predominantly Caucasian, and all were English speaking. The demographic profile limits the generalizability of findings to more heterogeneous populations and our ability to draw conclusions about the role of cultural and language barriers.

Women in the focus groups did not complete the BDI, possibly limiting conclusions about their perception of barriers. However, our observations indicate most women were speaking based on their own experiences or those of friends and family. This study is also limited by the exclusive use of self-report data. In addition, the access to treatment questionnaire has not yet been validated. The refusal rate for the survey and focus groups is unknown, potentially resulting in a biased sample. Additional data, such as insurance status and mental health history, would allow more conclusions to be drawn about the roles cost, insurance, income, and depressive symptom severity play in seeking care and how barriers relate to actual behavior.

An assessment of systems-level barriers to screening, referral, and provision of mental health care for pregnant women is critical for developing effective perinatal mental health services. Future research should examine the potential role of interventions that improve the quality of mental health care in non-mental health settings (18).

The real and perceived lack of antenatal mental health care that is readily available and visible, as well as perceived to be both affordable and of good quality, impedes access to care. In order to deliver effective treatment, we must focus on modifiable barriers and mechanisms for addressing them in partnerships between perinatal women and professionals in maternal health and mental health.

\section{Acknowledgments}

This study was supported by grant 1R01-MH-59103 from the National Institute of Mental Health (NIMH). Dr. Kopelman was supported by grant RR01-17700 from the National Institutes of Health and Dr. Stuart was supported by grant K24-MH-072757 from the NIMH. The authors wish to thank Allison Deere, BA, and Zarabeth Gerling, $\mathrm{BA}$, for their assistance in data collection and management.

\section{References}

1. O'Hara MW. Social support, life events, and depression during pregnancy and the puerperium. Archives of General Psychiatry. 1986; 43:569-573. [PubMed: 3707289]

2. Hobfoll SE, Ritter C, Lavin J, et al. Depression prevalence and incidence among inner-city pregnant and postpartum women. Journal of Consulting and Clinical Psychology. 1995; 63:445-453. [PubMed: 7608357]

3. Orr ST, James SA, Blackmore Prince C. Maternal prenatal depressive symptoms and spontaneous preterm births among African-American women in Baltimore, Maryland. American Journal of Epidemiology. 2002; 156:797-802. [PubMed: 12396996] 
4. Appleby L. Suicide during pregnancy and in the first postnatal year. British Medical Journal. 1991; 302:137-140. [PubMed: 1995132]

5. Miranda J, Azocar F, Komaromy M, et al. Unmet mental health needs of women in public-sector gynecologic clinics. American Journal of Obstetrics and Gynecology. 1998; 178:212-217. [PubMed: 9500476]

6. Scholle SH, Haskett RF, Hanusa BH, et al. Addressing depression in obstetrics/gynecology practice. General Hospital Psychiatry. 2003; 25:83-90. [PubMed: 12676420]

7. Stuart, S.; O'Hara, MW. Psychosocial treatments for mood disorders in women. In: Steiner, M.; Yonkers, KA.; Eriksson, E., editors. Mood Disorders in Women. London: Martin Dunitz; 2000.

8. Cohen LS, Altshuler LL, Harlow BL, et al. Relapse of major depression during pregnancy in women who maintain or discontinue antidepressant treatment. JAMA. 2006; 295:499-507. [PubMed: 16449615]

9. Smith MV, Rosenheck RA, Cavaleri MA, et al. Screening for and detection of depression, panic disorder, and PTSD in public-sector obstetric clinics. Psychiatric Services. 2004; 55:407-414. [PubMed: 15067153]

10. Miranda J, Green BL. The need for mental health services research focusing on poor young women. Journal of Mental Health Policy and Economics. 1999; 2:73-80. [PubMed: 11967411]

11. Alvidrez J, Azocar F. Distressed women's clinic patients: preferences for mental health treatments and perceived obstacles. General Hospital Psychiatry. 1999; 21:340-347. [PubMed: 10572775]

12. Creswell, J. Research Design: Qualitative, Quantitative and Mixed Methods Approaches. Thousand Oaks, Calif, Sage: 2003.

13. Beck AT, Ward CH, Mendelson M, et al. An inventory for measuring depression. Archives of General Psychiatry. 1961; 4:561-571. [PubMed: 13688369]

14. Pfost K, Stevens M. The relationship of demographic variables, antepartum depression, and stress to postpartum depression. Journal of Clinical Psychology. 1990; 46:588-592. [PubMed: 2246364]

15. Hill CE, Thompson BJ, Williams E. A guide to conducting consensual qualitative research. Counseling Psychologist. 1997; 25:517-572.

16. Miranda J, Chung JY, Green BL, et al. Treating depression in predominantly low-income young minority women: a randomized controlled trial. JAMA. 2003; 290:57-65. [PubMed: 12837712]

17. Webster J, Pritchard MA, Linnane JW, et al. Postnatal depression: use of health services and satisfaction with health-care providers. Journal of Quality in Clinical Practice. 2001; 21:144-148. [PubMed: 11856412]

18. Katon WJ, Unützer J. Pebbles in a pond: NIMH grants stimulate improvements in primary care treatment of depression. General Hospital Psychiatry. 2006; 28:185-188. [PubMed: 16675360] 


\section{Table 1}

Characteristics of women receiving prenatal care who completed measures of depressive symptomatology and who participated in focus groups about help seeking for depression

\begin{tabular}{|c|c|c|c|c|}
\hline \multirow[b]{2}{*}{ Variable } & \multicolumn{2}{|c|}{$\begin{array}{l}\text { Survey participants } \\
(\mathrm{N}=\mathbf{1 , 4 1 6 )}\end{array}$} & \multicolumn{2}{|c|}{$\begin{array}{l}\text { Focus group participants } \\
(\mathbf{N}=\mathbf{2 8})\end{array}$} \\
\hline & $\mathbf{N}$ & $\%$ & $\mathbf{N}$ & $\%$ \\
\hline Age $(\mathrm{M} \pm \mathrm{SD})$ & $27.7 \pm 5.7$ & & $25 \pm 4$ & \\
\hline \multicolumn{5}{|l|}{ Marital status } \\
\hline Married & 907 & 64 & 10 & 36 \\
\hline Living with partner & 199 & 14 & 7 & 25 \\
\hline \multicolumn{5}{|l|}{ Race or ethnicity } \\
\hline Caucasian & 1160 & 82 & 18 & 64 \\
\hline Hispanic & 90 & 6 & 3 & 11 \\
\hline African American & 55 & 4 & 4 & 14 \\
\hline Asian or Pacific Islander & 50 & 4 & 1 & 4 \\
\hline American Indian & 16 & 1 & 0 & - \\
\hline Other & 31 & 2 & 2 & 7 \\
\hline Median total household income per year & $\$ 30,000-\$ 40,000$ & & $\$ 10,000-\$ 20,000$ & \\
\hline Total household income less than $\$ 10,000$ per year & 270 & 19 & 9 & 32 \\
\hline Working more than 15 hours per week & 803 & 57 & 6 & 21 \\
\hline Years of education $(\mathrm{M} \pm \mathrm{SD})$ & $14.55 \pm 2.88$ & & $13.03 \pm 1.95$ & \\
\hline Number of children $(\mathrm{M} \pm \mathrm{SD})$ & $.83 \pm 1.01$ & & $.96 \pm 1.14$ & \\
\hline Number of pregnancies $(\mathrm{M} \pm \mathrm{SD})$ & $2.14 \pm 1.53$ & & $2.15 \pm 1.38$ & \\
\hline BDI score $(\mathrm{M} \pm \mathrm{SD})^{a}$ & $8.80 \pm 6.55$ & & - & \\
\hline BDI score of 16 or greater ${ }^{a}$ & 183 & 13 & - & \\
\hline
\end{tabular}

${ }^{a}$ Beck Depression Inventory. Possible scores on the BDI range from 0 to 63 , with higher scores indicating more depressive symptomatology. A score of 16 or greater indicates possible depression. 


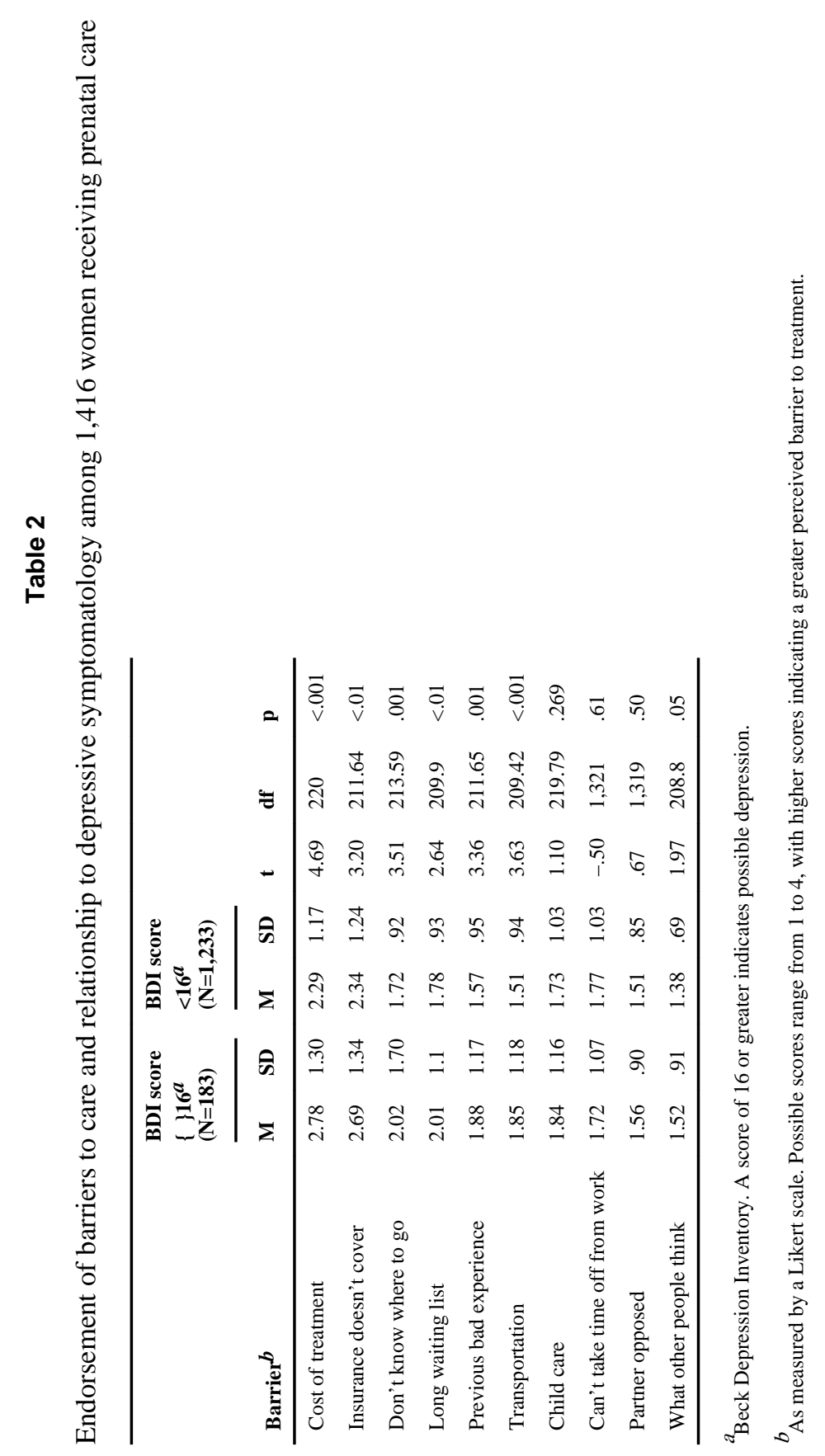

